Article

\title{
Investigation of the Effect of Nanocrystalline Calcium Carbonate-Substituted Hydroxyapatite and L-Lysine and L-Arginine Surface Interactions on the Molecular Properties of Dental Biomimetic Composites
}

\author{
Dmitry Goloshchapov ${ }^{1}$, Vladimir Kashkarov ${ }^{1}$, Kirill Nikitkov ${ }^{1}$ and Pavel Seredin ${ }^{1,2, *(D)}$ \\ 1 Solid State Physics and Nanostructures Department, Voronezh State University, University Sq. 1, \\ 394018 Voronezh, Russia; goloshchapovdl@gmail.com (D.G.); vmkashkarov@gmail.com (V.K.); \\ nikitkov.vsu@gmail.com (K.N.) \\ 2 Scientific and Educational Center "Nanomaterials and Nanotechnologies", Ural Federal, Mir Av., \\ 620002 Yekaterinburg, Russia \\ * Correspondence: paul@phys.vsu.ru
}

Citation: Goloshchapov, D.; Kashkarov, V.; Nikitkov, K.; Seredin, P. Investigation of the Effect of Nanocrystalline Calcium CarbonateSubstituted Hydroxyapatite and L-Lysine and L-Arginine Surface Interactions on the Molecular Properties of Dental Biomimetic Composites. Biomimetics 2021, 6, 70 . https://doi.org/10.3390/ biomimetics 6040070

Academic Editor: Stanislav N. Gorb

Received: 19 November 2021 Accepted: 9 December 2021 Published: 10 December 2021

Publisher's Note: MDPI stays neutra with regard to jurisdictional claims in published maps and institutional affiliations.

Copyright: (c) 2021 by the authors. Licensee MDPI, Basel, Switzerland. This article is an open access article distributed under the terms and conditions of the Creative Commons Attribution (CC BY) license (https:// creativecommons.org/licenses/by/ $4.0 /)$.
Abstract: Differences in the surface interactions of non-stoichiometric nanocrystalline B-type carbonatesubstituted hydroxyapatite (n-cHAp) with the amino acids L-Lysine hydrochloride (L-LysHCl) and $\mathrm{L}$-Arginine hydrochloride $(\mathrm{L}-\mathrm{ArgHCl})$ in acidic and alkaline media were determined using structural and spectroscopic analysis methods. The obtained data confirm that hydroxyapatite synthesized using our technique, which was used to develop the n-cHAp/L-LysHCl and n-cHAp/L$\mathrm{ArgHCl}$ composites, is nanocrystalline. Studies of molecular composition of the samples by Fourier transform infrared spectroscopy under the change in the charge state of L-Lysine in environments with different alkalinity are consistent with the results of X-ray diffraction analysis, as evidenced by the redistribution of the modes' intensities in the spectra that is correlated with the side chains, i.e., amide and carboxyl groups, of the amino acid. During the formation of a biomimetic composite containing L-Lysine hydrochloride and n-cHAp, the interaction occurred through bonding of the L-Lysine side chain and the hydroxyl groups of hydroxyapatite, which created an anionic form of L-Lysine at $\mathrm{pH} \leq 5$. In contrast, in biocomposites based on L-Arginine and n-cHAp, the interaction only slightly depends on $\mathrm{pH}$ value, and it proceeds by molecular orientation mechanisms. The X-ray diffraction and infrared spectroscopy results confirm that changes in the molecular composition of $\mathrm{n}$-cHAp/L-ArgHCl biomimetic composites are caused by the electrostatic interaction between the $\mathrm{L}-\mathrm{ArgHCl}$ molecule and the carbonate-substituted calcium hydroxyapatite. In this case, the bond formation was detected by Fourier transform infrared (FTIR) spectroscopy; the vibrational modes attributed to the main carbon chain and the guanidine group of L-Arginine are shifted during the interaction. The discovered interaction mechanisms between nanocrystalline carbonate-substituted hydroxyapatite that has physicochemical properties characteristic of the apatite in human dental enamel and specific amino acids are important for selecting the formation conditions of biomimetic composites and their integration with the natural dental tissue.

Keywords: biocompatible materials; biomimetics; nanocrystalline carbonate-substituted hydroxyapatite; L-Lysine; L-Arginine; macromolecular substances; molecular properties; interaction

\section{Introduction}

Biomimetic composites containing an organic matrix and inorganic phosphate components are promising materials for restorative and regenerative dentistry, surgery and bone grafting [1-3]. The synthesis of such hybrid biomaterials, reproducing the physicochemical properties of human hard tissues [4-8], as well as the modification of biomaterials with different inorganic bioactive ions and molecular groups in order to initiate the con- 
trolled reaction in tissues and to provide antimicrobic activity, is a complex and multilevel task [9-12].

Within the framework of the biomimetic concept $[13,14]$, reproduction of the inorganic base of tooth enamel and dentin can be best achieved by using nanocrystalline carbonatesubstituted hydroxyapatite, n-cHAp, $\left(\mathrm{Ca}_{10}\left(\mathrm{PO}_{4}\right)_{6-\mathrm{x}}\left(\mathrm{CO}_{3}\right)_{\mathrm{x}}(\mathrm{OH})_{2-\mathrm{x}}, 0.1<\mathrm{x}<0.3\right)$, which is characterized by an excellent appropriateness with the properties of dental matrix apatite [1,15]. At the same time, a large amount of research considering the problem of dental tissue repair [5,16-19] has established the importance of using a combination of $\mathrm{n}$-cHAp and polar amino acids in dental biocomposites. As subunits of the protein matrix of teeth, amino acids perform many functions, including forming a biomimetic composite with the necessary configuration to compensate for surface and volume defects in enamel and dentition. Key factors in the formation of a stable bond between the organic (protein) matrix and the phosphate complexes are not only the presence of amino acid side chains, but also the presence of uncompensated charge on the surface of the mineral complexes [20-22] and the conditions chosen for the synthesis processes: solvent, temperature, and $\mathrm{pH}$ value $[23,24]$.

A large number of studies on the synthesis of composite materials have used amino acids in an anionic form, that is, at $\mathrm{pH}$ values above the isoelectric point $(\mathrm{pH}>8)[17,18,23,25,26]$. However, current enamel and dentin pre-treatment therapeutical procedures (the total-etch technique of tooth surface for chemically adhesive composite restorations), use strong acid-based solutions $(\mathrm{pH} \leq 2)$ [27]. This environment may lead to a different interaction mechanism not only between the components of the biomimetic composite, but also with the natural tissue being restored.

Thus, the issue of the mechanism of the hydroxyapatite-amino acid bond formation remains an important one, in addition to the determination of the molecular functional groups responsible for the processes of crystallisation $[19,26,28]$.

It should be noted that using various biomedical strategies, such as a direct mineralization from a solution [14], protein/peptide induction of mineralization [29,30], and assembly with the use of the ready subunits and precursors [10,31,32], no appropriate biomimetic technologies for the restoration of the hard dental tissue for its clinical application have yet been developed (similar to the cutaneous covering) [33-35]; this means that the problem of the imitation of the natural interaction between organic-mineral components in the synthesized materials still remains open-ended.

Therefore, this study aimed to obtain biomimetic materials reproducing the properties of the natural hard dental tissue of a human based on nanocrystalline hydroxyapatite and amino acids (L-Lysine and L-Arginine) by changing their charge state, and, for the first time, to perform a comprehensive study of the regularities and the effects of the surface interaction mechanisms on the molecular properties of these biomimetic composites using structural and spectroscopic methods.

\section{Materials and Methods}

\subsection{Methodology for Obtaining Samples}

The formation of the biomimetic composites was conducted in an aqueous medium and occurred in several stages with the preparation of solutions containing the inorganic and organic components. Aqueous solutions were used because hydroxyapatite at the chosen synthesis conditions contains a hydrated layer through which the ion-exchange reactions occur [36]. Chemical precipitation using a biogenic calcium source according to the method described in [37] was used to obtain n-cHAp that reproduced the features of the enamel apatite. The crystal structure of the n-cHAp samples synthesized in our work is characterized by the substitution of the phosphate ion $\mathrm{PO}_{4}{ }^{3-}$ by $\mathrm{CO}_{3}{ }^{2-}$ group (B-type of substitution) in hydroxyapatite crystal lattice.

First, a homogeneous suspension containing n-cHAp was prepared. This approach resulted in a solution containing hydroxyapatite nanocrystals with a high specific surface area [37]. After conditioning the solution for $24 \mathrm{~h}$ to form a homogenous solution; this solution containing $n$-cHAp was subjected to ultrasonic stirring for prevention of the 
agglomeration of crystals. A Sonica Q55 55W ultrasonic homogeniser was used for this purpose, operating at the amplitude of 50 for $5 \mathrm{~min}$. Concentration of the $\mathrm{n}$-cHAp in homogeneous suspension was at most $18.8 \mathrm{mg} / \mathrm{mL}$.

Aqueous solutions of amino acids were prepared using L-Lysine hydrochloride ( $\mathrm{L}-\mathrm{LysHCl})$ and L-Arginine hydrochloride ( $\mathrm{L}-\mathrm{ArgHCl})$ powders. The concentration of the amino acids was at most $10 \mathrm{mg} / \mathrm{mL}$. These amino acids were dissolved in ultrapure water (Millipore Milli-Q gradient ultrapure water system, Q-Guard 1, QGARDOOR1, with $0.22 \mu \mathrm{m}$ Millipore MILLIPAK Express 0575, MPGP02001) and sonicated (Q55 Sonica 55W) at a $50 \%$ amplitude for $5 \mathrm{~min}$. The choice of the hydrochloride forms of amino acids is because polar amino acids are bound to molecules of various mineral complexes and ions in many processes, and these complexes can mediate their interaction with biogenic hydroxyapatite.

To study the changes in the charge state of the amino acids, aqueous solutions of $\mathrm{L}-\mathrm{LysHCl}$ and $\mathrm{L}-\mathrm{ArgHCl}$ with different $\mathrm{pH}$ values were prepared. For this purpose, aqueous solutions of ammonia $\left(\mathrm{NH}_{4} \mathrm{OH}\right)$ and hydrochloric acid $(\mathrm{HCl})$ were added to the aqueous solutions of amino acids to obtain solutions of $\mathrm{pH} \geq 11.2, \geq 7.5$ and $\leq 5$. $\mathrm{pH}$ values were measured with an Orion $420 \mathrm{~A} \mathrm{pH}$ meter, and the electrode was cleaned with water before and after each measurement. For the calibration, pH-buffer solutions were used.

In the last step, thus prepared aqueous solutions of n-cHAp and L-Lysine or L-Arginine were mechanically mixed to form a homogeneous suspension and subjected to ultrasonic agitation (Q55 Sonica $55 \mathrm{~W}$ ) at the amplitude of $50 \%$ for $10 \mathrm{~s}$. The concentration of the n-cHAp to amino acids in the final solutions attained approximately 2:1. The resulting samples were dried for $24 \mathrm{~h}$ at $20^{\circ} \mathrm{C}$. As a result, n-cHAp/L-LysHCl and n-cHAp/L$\mathrm{ArgHCl}$ biocomposites were crystallised with different $\mathrm{pH}$ levels.

\subsection{Methods of Structural and Spectroscopic Analysis of the Samples}

\subsubsection{X-ray Structural Analysis}

Phase composition of all the samples was investigated using a DRON-4-07 X-ray diffractometer. The $X$-ray source was an X-ray tube with a cobalt anode $(\lambda=1.7902 \AA)$ at the voltage of $26 \mathrm{kV}$ and current of $15 \mathrm{~mA}$. Phase analysis was performed using the JCPDS-ICDD database.

\subsubsection{Optical Microscopy}

Optical images of the samples in the light field were obtained at $1000 \times$ magnification using a CX41 Olympus optical microscope.

\subsubsection{Transmission Electron Microscopy (TEM)}

The TEM technique was used for visualisation of n-cHAp nanocrystals. The study was carried out with the electron microscope Libra 120 Carl Zeiss.

\subsubsection{Fourier Transform Infrared (FTIR) Spectroscopy}

FTIR absorption spectra of the composites in the range $4500-400 \mathrm{~cm}^{-1}$. and spectral resolution of $2 \mathrm{~cm}^{-1}$ were recorded at the Infrared Microspectroscopy (IRM) beamline (Australian synchrotron, Clayton, VIC, Australia) using a Bruker Vertex 80v spectrometer coupled with a Hyperion 2000 FTIR microscope and a liquid nitrogen-cooled narrow-band mercury cadmium telluride (MCT) detector (Bruker Optik, Germany) [38-40]. BlackmanHarris 3-term apodization, Mertz phase correction, and a zero-filling factor of 2 were set as default acquisition parameters using the OPUS 7.2 software suite (Bruker Optik, Germany).

\subsubsection{Information about Diagnostic Methods Used in Work, Provided for Comparison}

Comparative information about structural and spectroscopic methods of analysis used in our work is presented in Table 1. 
Table 1. Methods of structural and spectroscopic analysis.

\begin{tabular}{cccc}
\hline Detection Features & X-ray Structural Analysis & $\begin{array}{c}\text { Synchrotron Fourier } \\
\text { Transform Infrared } \\
\text { Spectroscopy }\end{array}$ & $\begin{array}{c}\text { Transmission Electron } \\
\text { Microscopy }\end{array}$ \\
\cline { 2 - 5 } Identification & Crystalline structure & Molecular and chemical bonds & $\begin{array}{c}\text { Morphology of compounds, } \\
\text { surface geometry }\end{array}$ \\
\hline Source for characterisation & X-rays & $\begin{array}{c}\text { Synchrotron radiation in } \\
\text { Infrared range of spectrum }\end{array}$ & Electrons \\
\hline Description & Angstrom & cm ${ }^{-1}$ & nm \\
\hline & $\begin{array}{c}\text { Providing information on } \\
\text { structures, phases, preferred } \\
\text { crystal orientations (texture), } \\
\text { and other structural } \\
\text { parameters of the dried } \\
\text { solution samples }\end{array}$ & $\begin{array}{c}\text { Identify or characterize } \\
\text { organic/bio materials through } \\
\text { creating a spectrum that } \\
\text { shows molecular vibrations }\end{array}$ & $\begin{array}{c}\text { Imagining and } \\
\text { characterization of } \\
\text { nanoparticles with high } \\
\text { spatial resolution }\end{array}$ \\
\hline
\end{tabular}

\section{Results}

When the $\mathrm{pH}$ factor of the medium changes, the conformational environment of the amino acids is subjected to changes, which may affect the molecular structure of the biomimetic composite [16,41,42]. Therefore, the structural and molecular properties of the amino acids $\mathrm{L}-\mathrm{LysHCl}$ and $\mathrm{L}-\mathrm{ArgHCl}$ crystallised from solutions with different $\mathrm{pH}$ values were compared with the properties of $\mathrm{n}$-cHAp/L-LysHCl and n-cHAp/L-ArgHCl biomimetic composites obtained under the same conditions and $\mathrm{pH}$ values, in order to establish the influence of the charge state of amino acids on the final biocomposite.

\subsection{X-ray Diffractometry}

Figure 1 shows the X-ray diffraction analysis (XRD) scans of amino acids L-LysHCl and $\mathrm{L}-\mathrm{ArgHCl}$ before dissolution (in powder form) and crystallised from solutions with different $\mathrm{pH}$ values: $\geq 11.2, \geq 7.5$ and $\leq 5$.

The X-ray diffraction results (Figure 1) demonstrate heterogeneous behaviour of L-Lysine and L-Arginine after crystallisation from a neutral medium $(\mathrm{pH} \geq 7.55)$. The samples of L-Lysine crystallised from solution are characterised by the appearance of texture; that is, the dissolution and subsequent crystallisation of the L-Lysine changes the direction of the preferential orientation of the amino acid crystals (Figure 1a, curves 2, 3, 4). This change is represented in the increased intensity in the region of $2 \theta=27.9^{\circ}$. At the same time, the intensity of other diffraction lines decreases proportionally. As has been repeatedly shown $[18,43]$, the dissolution of amino acids in an aqueous medium and their subsequent crystallisation changes the conformational environment of the amino acid molecule. Therefore, peaks appear in the region of $2 \theta=27.9^{\circ}, 29.0^{\circ}, 36.7^{\circ}$ and $43.6^{\circ}$ that were not observed in the diffraction spectrum of the original hydrochloride form of L-Lysine (Figure 1a). This analysis shows that a change in the charge state of the amino acid (above and below the isoelectric point of $\mathrm{pH}=8.7$ ) is observed as a redistribution of the intensity of the main diffraction reflexes. With increasing $\mathrm{pH}$ of the medium from which L-Lysine was crystallised, X-ray lines corresponding to pure L-Lysine (sample PDF Card-00-005-0397) increase their intensity (Figure 1a). 

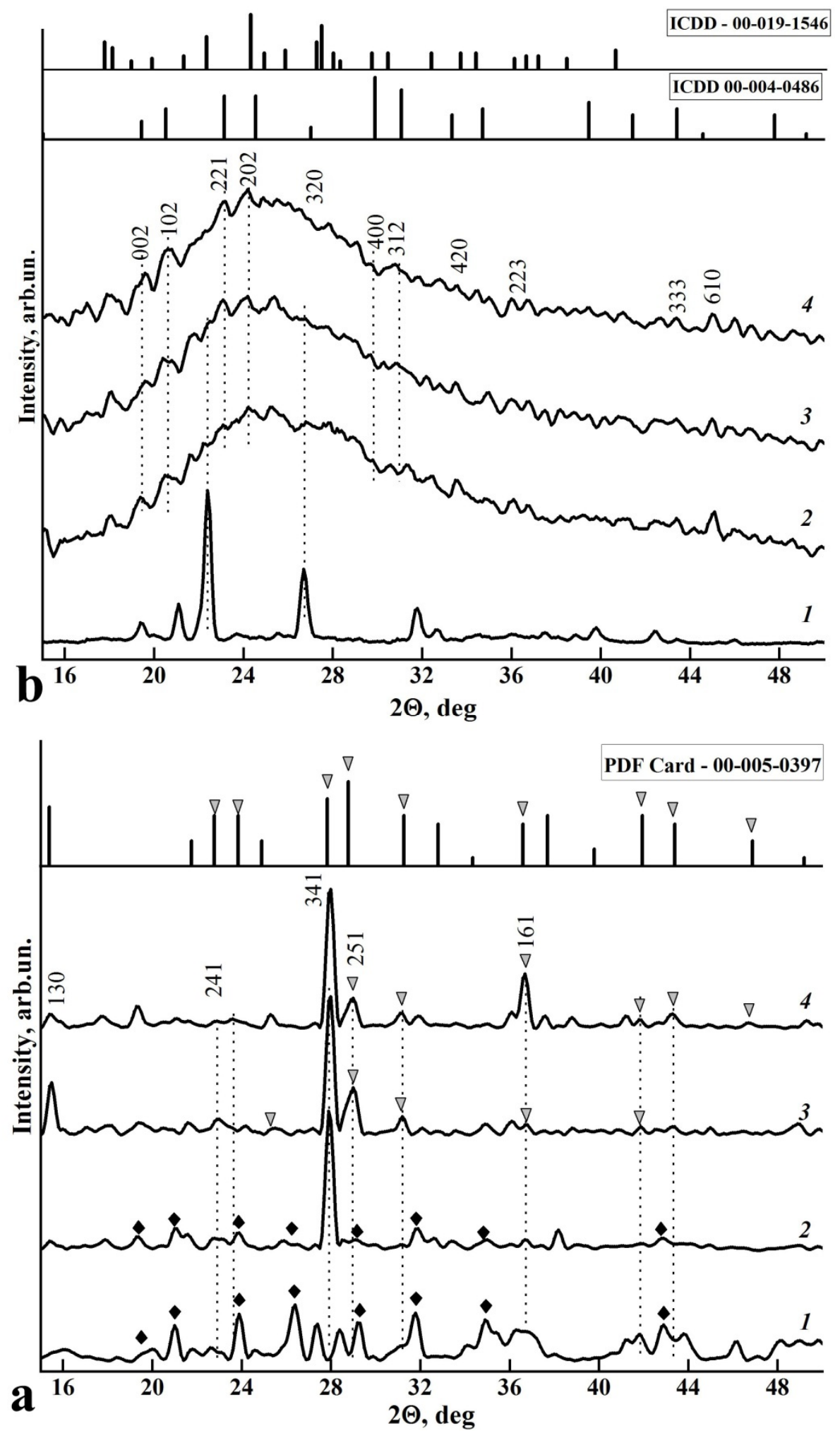

Figure 1. XRD scans of amino acid samples: (a) L-Lys $\mathrm{HCl}$ in the original crystalline state (curve 1) and crystallised from solutions at $\mathrm{pH} \leq 5$ (curve 2), $\mathrm{pH} \geq 7.5$ (curve 3 ) and $\mathrm{pH} \geq 11.2$ (curve 4). (b) $\mathrm{L}$ - $\mathrm{ArgHCl}$ in the original crystalline state (curve 1) and crystallised from solutions with $\mathrm{pH} \leq 5$ (curve 2), $\mathrm{pH} \geq 7.5$ (curve 3) and $\mathrm{pH} \geq 11.2$ (curve 4). $\mathbf{\nabla}$-L-Lys diffraction reflexes, $-\mathrm{L}-\mathrm{LysHCl}$ diffraction reflexes. ICDD database data: L-Lysine-ICDD Card 00-005-0397; L-Arginine-ICDD Card 00-004-0486 and 00-019-1546. 
In contrast, the samples of L-Arginine crystallised from solutions are characterised by the appearance of amorphous phases. Figure $1 \mathrm{~b}$ shows the diffractograms of powdered L-ArgHCl (curve 1) and the samples obtained following the dissolution and recrystallisation of $\mathrm{L}-\mathrm{ArgHCl}$ in media with different $\mathrm{pH}$ values: $\geq 11.2, \geq 7.5$ and $\leq 5$ (curves $2,3,4$ ). In the background of the wide halo at $2 \theta=15-50^{\circ}$, low-intensity reflexes near $2 \theta=19.5^{\circ}, 20.7^{\circ}, 23.2^{\circ}, 24.3^{\circ}$, $29.7^{\circ}, 30.9^{\circ}$ and $43.3^{\circ}$ are observed, which are in agreement with the L-Arginine phase (ICDD 00-004-0486 and 00-019-1546). The width and intensity of the detected lines and their agreement with the ICDD data indicate a distortion in the conformational environment of L-Arginine hydrochloride and the presence of disordered amorphous phase in all samples after their crystallisation (Figure 1b).

The diffractograms of the n-cHAp/L-LysHCl and n-cHAp/L-ArgHCl biocomposites containing nanocrystalline B-type substituted hydroxyapatite and the amino acids L-Lysine and L-Arginine are shown in Figures $2 \mathrm{a}$ and $2 \mathrm{~b}$, respectively.

The X-ray diffraction data of n-cHAp/L-LysHCl and n-cHAp/L-ArgHCl samples show that all diffraction reflections belong to calcium hydroxyapatite-substituted carbonate (ICDD 01-074-0565), L-Lysine hydrochloride (PDF Card 00-005-0397) or L-Arginine hydrochloride (PDF Card 00-004-0486 and PDF Card 00-019-1546), respectively. There is a redistribution of $X$-ray reflection intensities relative to ICDD data. A detailed examination of the XRD data of these biocomposites indicates the changes in the conformational environment of the amino acids in the presence of n-cHAp hydroxyapatite, distinct from those ones observed for the samples of the corresponding amino acids crystallised after dissolution at the same $\mathrm{pH}$ values (Figure 2). Moreover, the results show that L-Arginine hydrochloride retains its amorphous structure in the presence of hydroxyapatite.

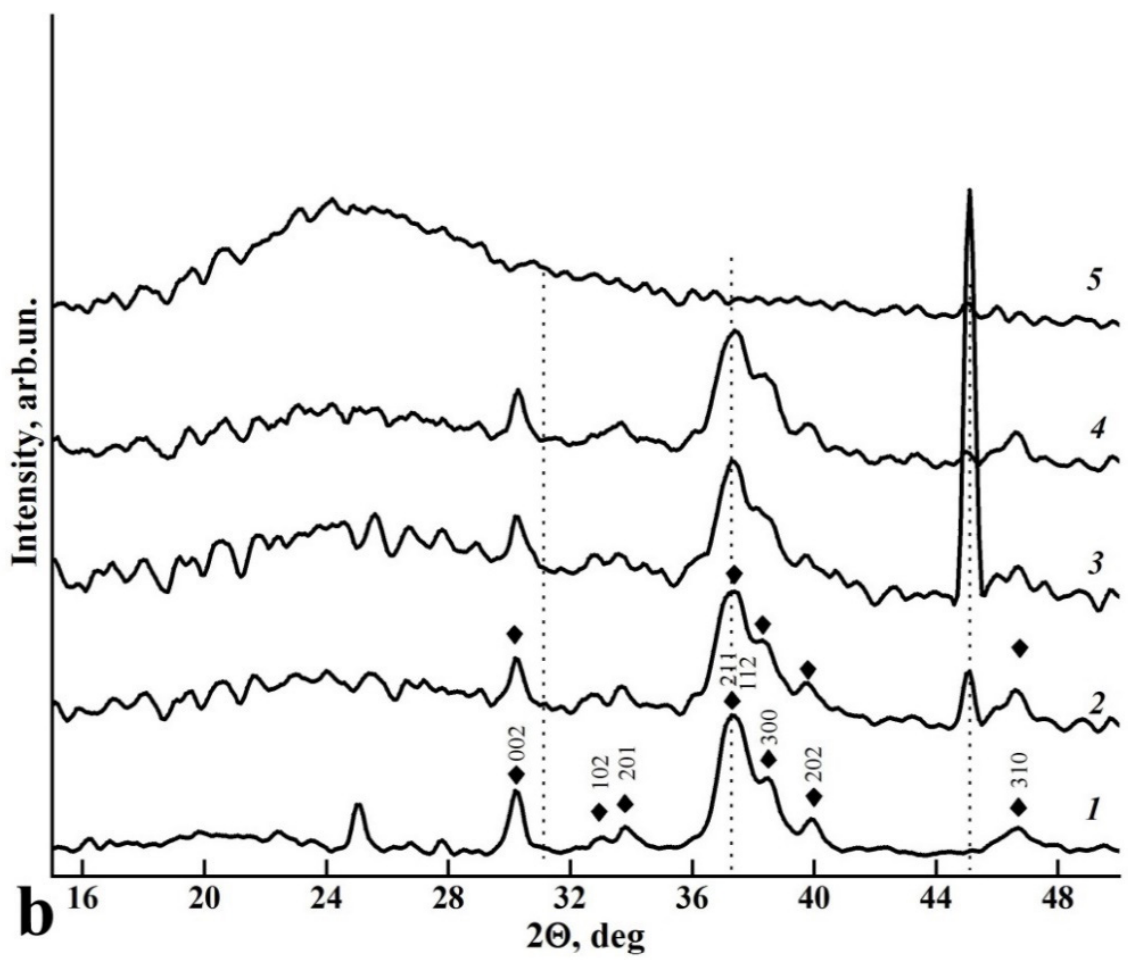

Figure 2. Cont. 


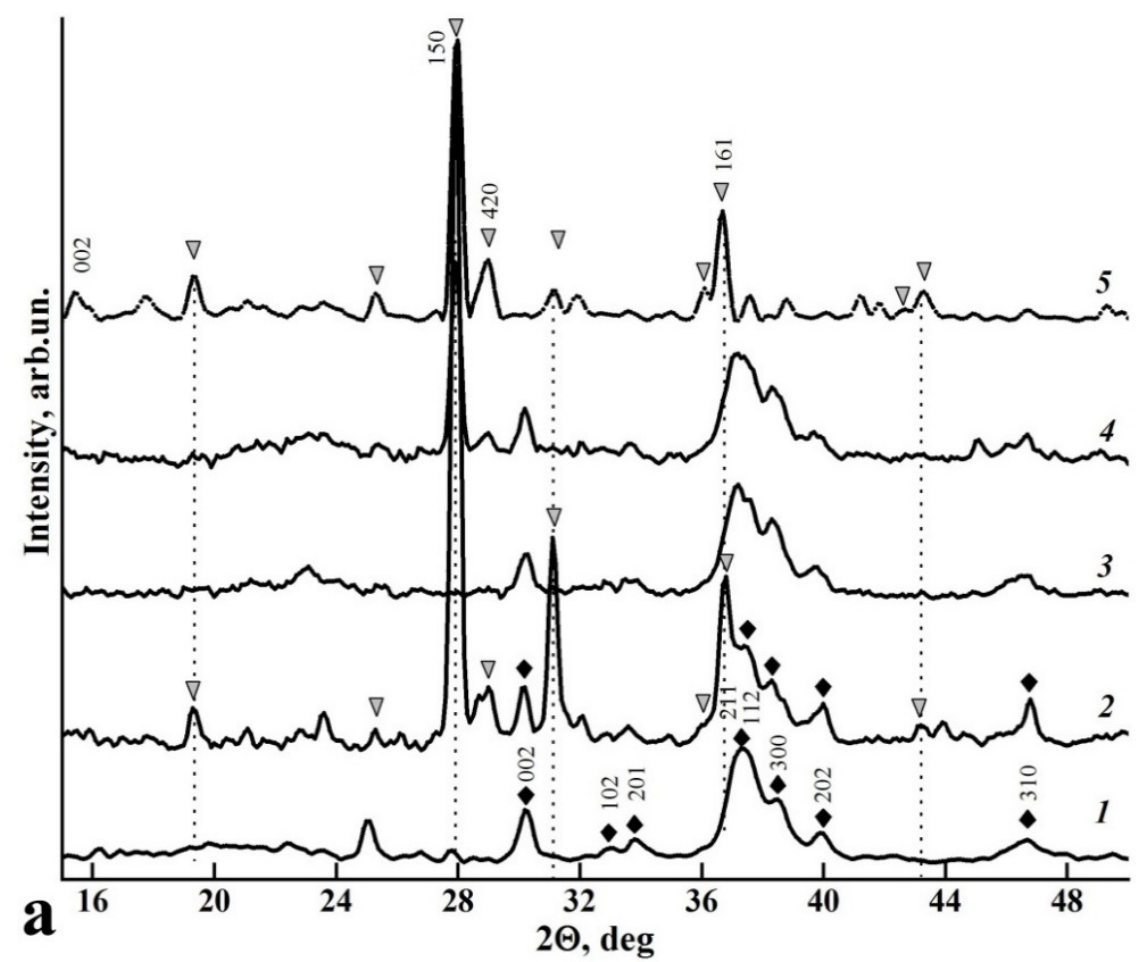

Figure 2. XRD scans of the biocomposite samples: (a) n-cHAp (curve 1); n-cHAp/L-LysHCl biocomposites obtained from solutions of $\mathrm{pH} \leq 5$ (curve 2), $\mathrm{pH} \geq 7.5$ (curve 3 ) and $\mathrm{pH} \geq 11.2$ (curve 4); L-Lys $\mathrm{HCl}$ amino acid sample obtained by crystallisation from solution with $\mathrm{pH} \geq 11.2$ (curve 5). (b) n-cHAp (curve 1); n-cHAp/L-ArgHCl biocomposites obtained from solutions with $\mathrm{pH}<5$ (curve 2), $\mathrm{pH} \geq 7.5$ (curve 3), and $\mathrm{pH} \geq 11.2$ (curve 4); $\mathrm{L}-\mathrm{ArgHCl}$ amino acid sample obtained by crystallisation from a solution with $\mathrm{pH} \geq 11.2$ (curve 5). $\mathbf{\nabla}$-diffraction reflexes of $\mathrm{L}-\mathrm{LysHCl}, \downarrow$-diffraction reflexes of n-cHAp.

Thus, for the $\mathrm{n}$-cHAp/L-LysHCl composites crystallised from solutions with $\mathrm{pH}<5$ (Figure 2a, curve 2), an increase in the intensity of diffraction lines $2 \theta=19.3^{\circ}, 25.3^{\circ}, 31.2^{\circ}$, $36.0^{\circ}, 36.7^{\circ}, 43.3^{\circ}$ and $46.7^{\circ}$ was observed. A similar ratio of intensities of the mentioned reflexes was observed for the L-LysHCl sample crystallised from the solution at $\mathrm{pH}>11.2$ (Figure 2a, curve 5). Comparison of the X-ray diffraction data shows that the distribution of X-ray diffraction intensities for the n-cHAp/L-LysHCl composite crystallised from a solution with $\mathrm{pH}>11.2$ corresponds to the L-LysHCl sample obtained from solutions with $\mathrm{pH}<5$ and $\mathrm{pH}=7.5$ (Figure 2a).

Regarding the hydroxyapatite included in the biocomposites (Figure 2a, curve 1), a redistribution of intensity of the main diffraction reflexes of n-cHAp (112), (202) and (002) was observed for the samples n-cHAp/L-LysHCl (Figure 2a, curve 2, 3, 4). The intensity of the (112) and (202) reflex is reduced relative to the intensity of reflex (002), which means a possible occurrence of the texture-the directional agglomeration of hydroxyapatite in the sample (Figure 2a).

\subsection{Microscopy}

Given a high content of nanocrystalline hydroxyapatite in the amino acid complexes of the samples, the resulting biocomposites were examined using light field optical microscopy. Figure 3 shows images of the surface morphology of the n-cHAp/L-LysHCl and n-cHAp/LArgHCl composites (1000× magnification). The inset in Figure 3 represents the TEM image of n-cHAp nanocrystals, obtained in the work. 


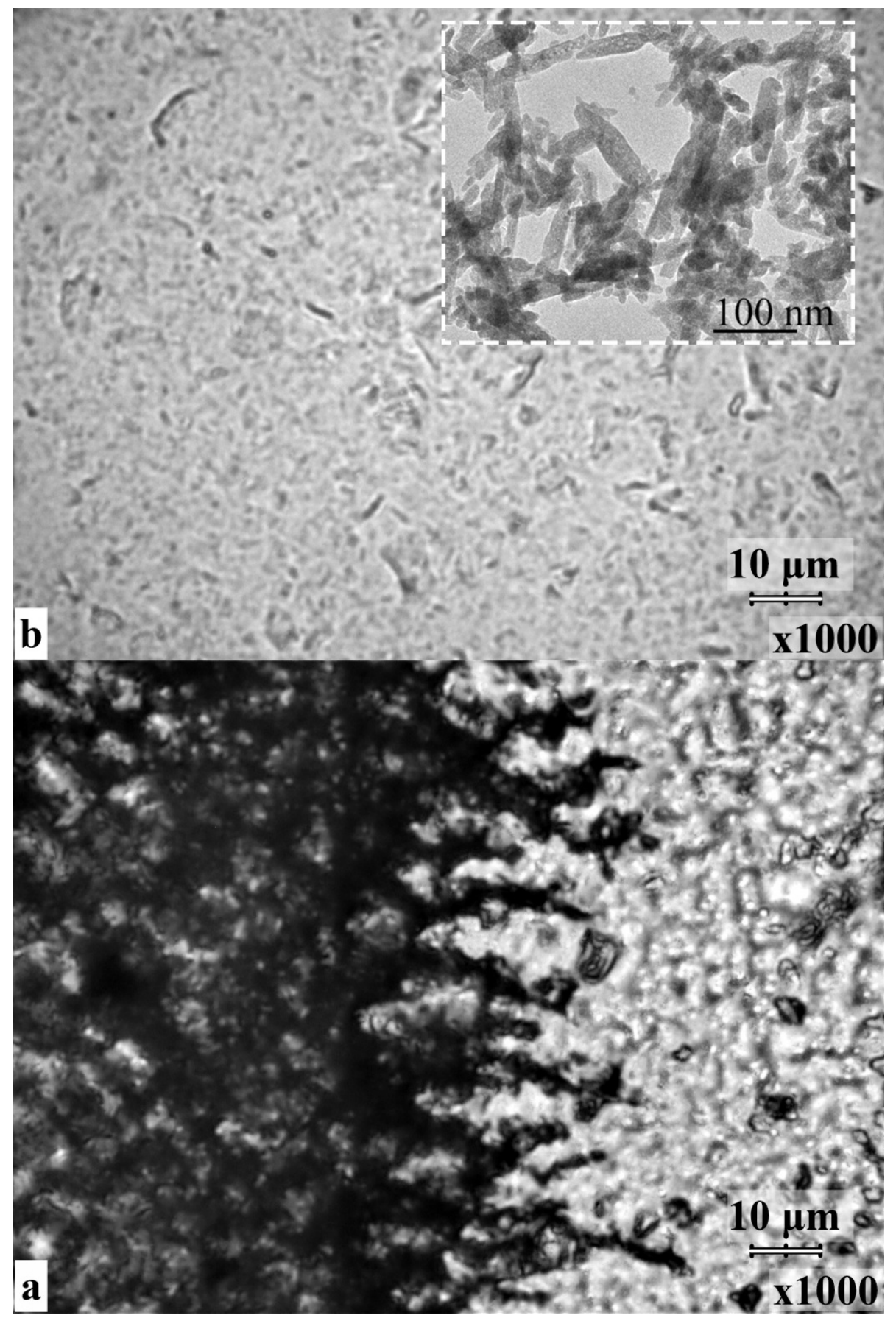

Figure 3. Optical images of the surface for the biocomposites (1000 $\times$ magnification) (a) n-cHAp/LLysHCl ( $\mathrm{pH} \geq 11.2$ ); (b) n-cHAp/L-ArgHCl ( $\mathrm{pH} \geq 11.2$ ). In the inset, the TEM image of $\mathrm{n}$-cHAP nanocrystals used for the preparation of the composite is presented.

From the optical images of the n-cHAp/L-LysHCl sample (Figure 3a), the aggregation of hydroxyapatite particles in the biocomposite occurred on the surfaces of all the samples. Thus, the formation of large conjugates with the approximate dimensions $2 \times 20 \mu \mathrm{m}$, oriented along a particular direction, is quite characteristic (Figure 3a). All of the particles and agglomerates of n-cHAp/L-LysHCl sample involve n-cHAp nanocrystals shown in the inset of Figure 3. In comparison, the n-cHAp/L-ArgHCl biocomposite surface is characterised by the presence of only a few large particles (Figure $3 b$ ) among a homogeneous suspension, with the main mass being $\sim 1 \mu \mathrm{m}$ smaller agglomerates. The 
single large agglomerates were predominantly of the spherical or oval shape and 2-15 $\mu \mathrm{m}$ in diameter.

\subsection{FTIR Spectroscopy}

A number of studies on calcium hydroxyapatite and amino acid-based biocomposites have repeatedly demonstrated the effectiveness of Fourier transform infrared spectroscopy for analysing changes in the molecular composition of the samples [18,41,44]. In addition, as it is noted in [43,45-47], the activity of amino acid side chains can be determined from their vibrational spectra and they represent the conformational changes of molecules in different environments. Therefore, the use of FTIR spectroscopy, sensitive to molecular transformations, is to study the mechanisms of conjugation of proteins and mineral components in biocomposites to be optimal $[40,48,49]$.

Figures 4 and 5 show FTIR spectra of L-LysHCl and L-ArgHCl crystallised from solutions with different $\mathrm{pH}$ values, and the spectra of the n-cHAp/L-LysHCl and n-cHAp/LArgHCl biocomposites containing nanocrystalline B-type substituted hydroxyapatite obtained under similar conditions. In addition, the figures show the FTIR absorption spectra of the amino acids $\mathrm{L}-\mathrm{LysHCl}$ and $\mathrm{L}-\mathrm{ArgHCl}$ in their original crystalline state. The active modes in the FTIR spectra of the respective samples are listed in Tables 2 and 3.

The FTIR spectra of the L-LysHCl samples (Figure 4a) show that, relative to the neutral $\mathrm{pH} \geq 7.5$, the increase and decrease of the hydrogen potential led to a redistribution of the intensity of the characteristic vibrational bands of different L-Lysine functional groups. This change reflects the variation of the charge state of the amino acid. According to the current interpretation, the $\mathrm{NH}_{3}{ }^{+}$and $\mathrm{COO}^{-}$side chains of amino acids should show the most prominent changes $[16,41,50]$. The intensities of the modes localised around $1637-1610 \mathrm{~cm}^{-1}$ and $1220,1182,805 \mathrm{~cm}^{-1}$, which are related to the amide $\left(\mathrm{NH}_{3}\right)$ groups of L-Lysine, were noticeably redistributed depending on the $\mathrm{pH}$ value. In the case of increased alkalinity (Figure 4a, curve 3,4), the $\mathrm{COO}^{-}$group vibration at $1415 \mathrm{~cm}^{-1}$ increased its intensity. Likewise, in an acidic medium, there was a slight redistribution of intensity of the $1530 \mathrm{~cm}^{-1}$ modes attributed to vibrations of the amide group (Figure 4a, curve 2). The bands in the spectrum corresponding to the rocking vibrations of the amide group $\left(\rho, \mathrm{NH}_{3}{ }^{+}\right)$at $1186 \mathrm{~cm}^{-1}$ and $1220 \mathrm{~cm}^{-1}$ strongly decrease up to background intensity in the case of the sample that crystallised from solutions at $\mathrm{pH} \geq 11.2$ (Figure $4 \mathrm{a}$, curve 4). The spectral feature in the form of a shoulder near $1470-1460 \mathrm{~cm}^{-1}$ attributed to the strain vibrations of $\mathrm{CH}_{2}$ groups became moderately intense. In the range of $1010-930 \mathrm{~cm}^{-1}$, there was also a slight redistribution of intensities of the vibrations attributed to $\mathrm{C}-\mathrm{C}$ bonds.

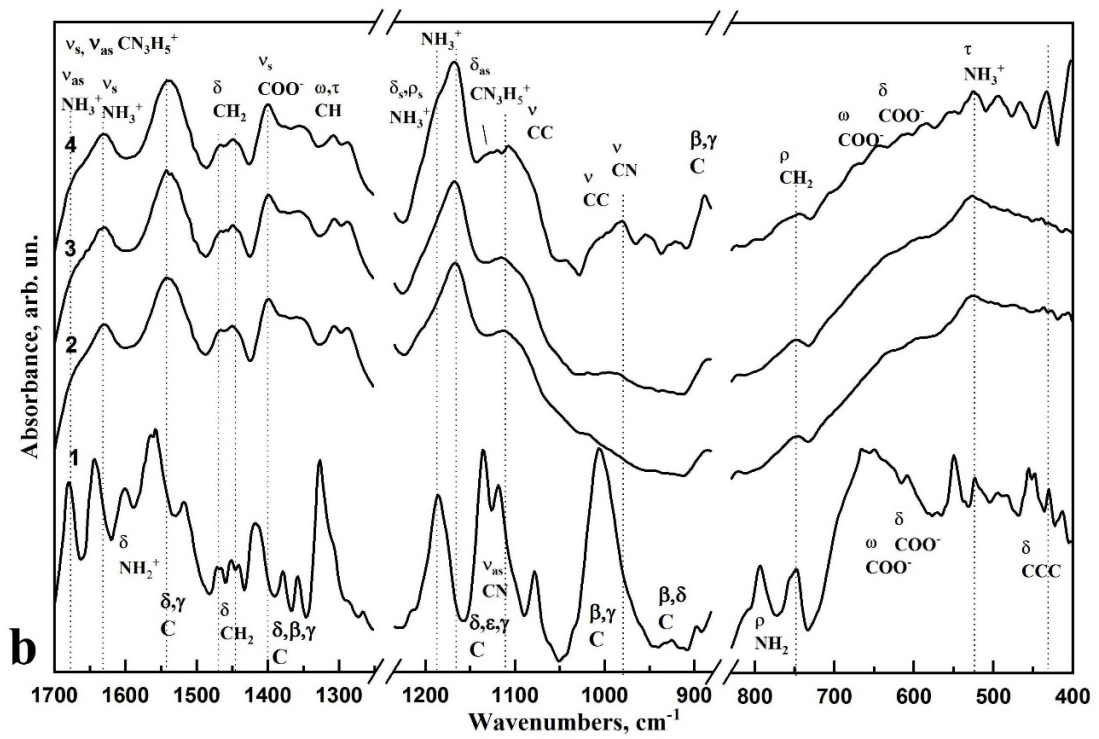

Figure 4. Cont. 


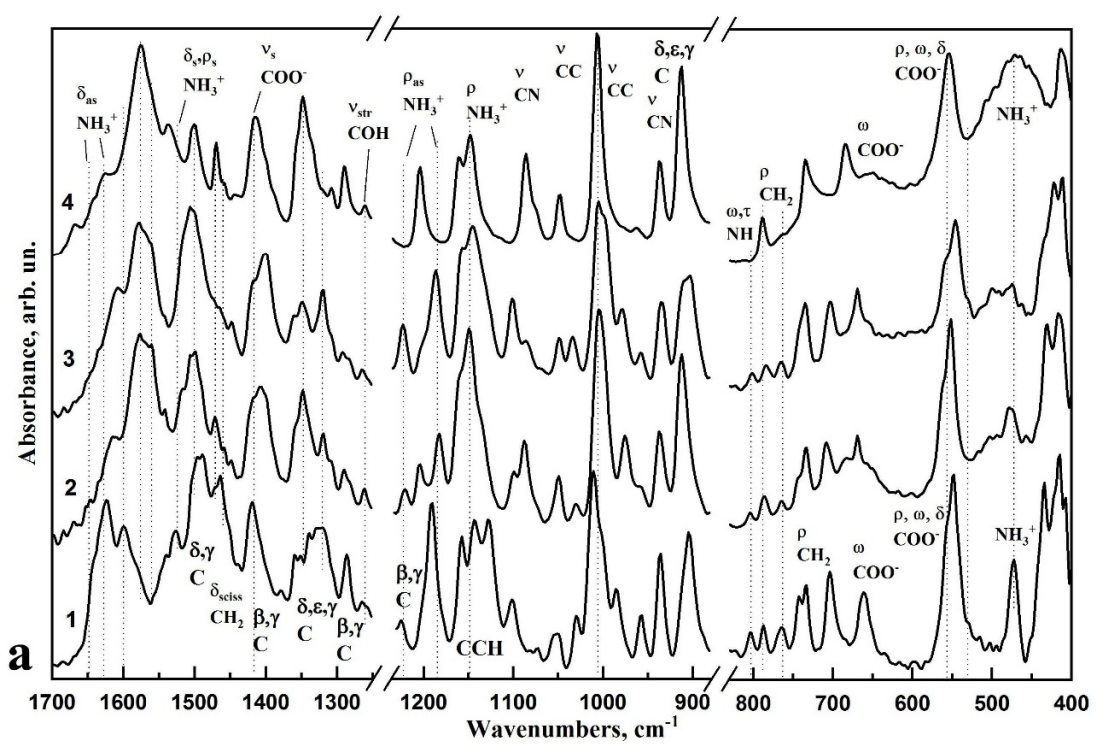

Figure 4. FTIR absorption spectra of the amino acid samples: (a) L-LysHCl in the original crystalline state (curve 1 ) and crystallised from solutions at $\mathrm{pH} \leq 5$ (curve 2), $\mathrm{pH} \geq 7.5$ (curve 3) and $\mathrm{pH} \geq 11.2$ (curve 4); (b) L-ArgHCl in the original crystalline state (curve 1) and crystallised from solutions at $\mathrm{pH} \leq 5$ (curve 2), $\mathrm{pH} \geq 7.5$ (curve 3 ) and $\mathrm{pH} \geq 11.2$ (curve 4).

In addition, in the range of $780-700 \mathrm{~cm}^{-1}$, a redistribution of intensity of the modes correlated to the vibrations of the carboxyl $\left(\mathrm{CH}_{2}\right)$ groups of L-Lysine was observed. The intensities of the modes localised around 700-600 $\mathrm{cm}^{-1}$ and $560,550 \mathrm{~cm}^{-1}$ and related to the $\mathrm{COO}^{-}$groups of L-Lysine were redistributed depending on the $\mathrm{pH}$ value.

FTIR spectroscopic investigation of the molecular composition of $\mathrm{L}$ - $\mathrm{ArgHCl}$ samples (Figure $4 \mathrm{~b})$ revealed slight changes in the vibrations of $\mathrm{CH}_{2}$ and $\mathrm{CH}_{3}$ groups $\left(1466 \mathrm{~cm}^{-1}\right.$, $1449 \mathrm{~cm}^{-1}$, respectively), as well as of the amide bonds at 1204,1188 , and $1167 \mathrm{~cm}^{-1}$ that mostly reflect the modification of the arginine chain molecules in media with changing acidity.

The FTIR spectra of $\mathrm{n}$-cHAp/L-LysHCl and n-cHAp/L-ArgHCl biocomposites containing nanocrystalline B-type substituted hydroxyapatite are shown in Figures $5 a$ and $5 b$, respectively. In addition, the figures show the absorption spectra of n-cHAp nanocrystalline B-type substituted hydroxyapatite synthesised in this study, and the amino acids $\mathrm{L}-\mathrm{LysHCl}$ and $\mathrm{L}-\mathrm{ArgHCl}$ that were crystallised from solutions at $\mathrm{pH} \geq 11.2$.

In the infrared spectra of n-cHAp/L-LysHCl samples, redistribution of the intensity of the $v_{4}$ and $v_{3}$ modes of the phosphate group $\mathrm{PO}_{4}{ }^{3-}\left(602 \mathrm{~cm}^{-1}, 558 \mathrm{~cm}^{-1}, 1091 \mathrm{~cm}^{-1}\right.$, and $1024 \mathrm{~cm}^{-1}$, respectively), and a decrease in the intensity of the shoulder at $630 \mathrm{~cm}^{-1}$ correlated with the $\mathrm{OH}$ group of cHAp, are observed depending on the $\mathrm{pH}$ of the environment and the charge state of the amino acid (Figure 5a, curves 2, 3,4). An intensity redistribution and frequency shift of the bands attributed to the vibrations of $\mathrm{NH}_{3}{ }^{+}$and $\mathrm{COO}^{-}$side chains of L-Lysine around $1645-1609 \mathrm{~cm}^{-1}, 1220-1148 \mathrm{~cm}^{-1}$ and $1415,560-550 \mathrm{~cm}^{-1}$, respectively, were observed simultaneously with changes in the hydroxyapatite modes in the FTIR spectra of the biocomposites obtained in acid media (Figure 5a, curve 2). 

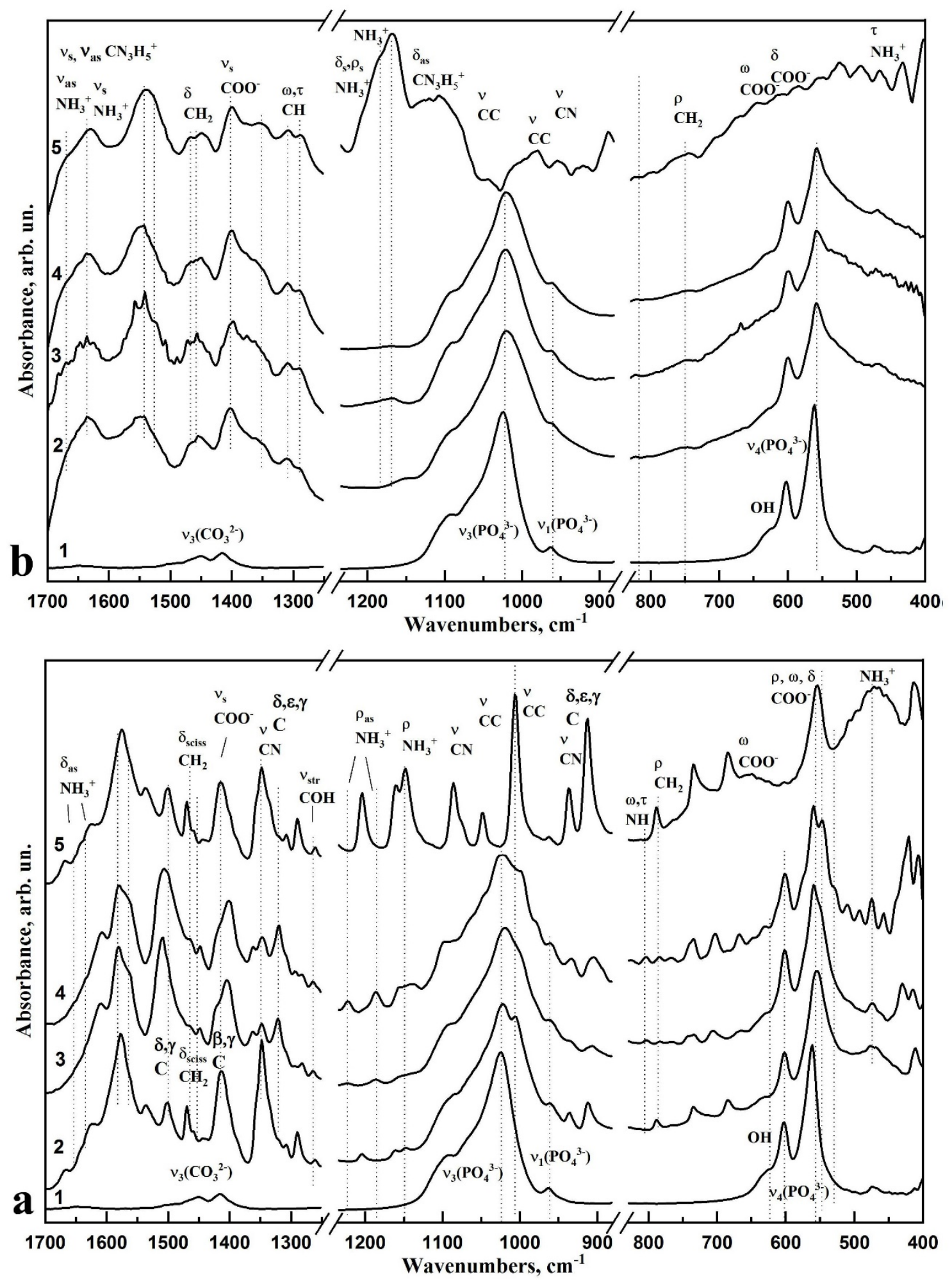

Figure 5. FTIR absorption spectra of biocomposite samples: (a) nanocrystalline B-type carbonate-substituted hydroxyapatite n-cHAp (curve 1), n-cHAp/L-LysHCl biocomposites obtained from solutions of $\mathrm{pH} \leq 5$ (curve 2), $\mathrm{pH} \geq 7.5$ (curve 3 ) and $\mathrm{pH} \geq 11.2$ (curve 4), L-LysHCl amino acid sample obtained by crystallisation from solution with $\mathrm{pH} \geq 11.2$ (curve 5); (b) nanocrystalline B-type carbonate-substituted hydroxyapatite n-cHAp (curve 1), n-cHAp/L-ArgHCl biocomposites obtained from solutions of $\mathrm{pH} \leq 5$ (curve 2), $\mathrm{pH} \geq 7.5$ (curve 3) and $\mathrm{pH} \geq 11.2$ (curve 4), $\mathrm{L}-\mathrm{ArgHCl}$ amino acid sample obtained by crystallisation from solution with $\mathrm{pH} \geq 11.2$ (curve 5). 
Table 2. Active modes in the FTIR absorption spectra of L-LysHCl samples and n-cHAp/L-LysHCl biocomposites, as well as their molecular group assignments.

\begin{tabular}{|c|c|c|c|c|c|c|c|}
\hline \multirow{3}{*}{ Active Modes } & \multicolumn{6}{|c|}{ Frequency of the Absorption Bands in the FTIR Spectra of the Samples, $\mathrm{cm}^{-1}$} & \multirow{3}{*}{$\begin{array}{c}\text { Ref.: Study } \\
\text { Reference Number }\end{array}$} \\
\hline & \multicolumn{3}{|c|}{ L-LysHCl } & \multicolumn{3}{|c|}{ n-cHAp/L-LysHCl Composites } & \\
\hline & $\mathrm{pH} \leq \mathbf{5}$ & $\mathrm{pH} \geq 7.5$ & $\mathrm{pH} \geq 11.2$ & $\mathrm{pH} \leq 5$ & $\mathrm{pH} \geq 7.5$ & $\mathrm{pH} \geq \mathbf{1 1 . 2}$ & \\
\hline \multirow{3}{*}{$\delta_{a s} \mathrm{NH}_{3}{ }^{+}$} & 1637 & 1635 & 1639 & 1642 & 1645 & 1651 & \multirow{3}{*}[41,46,47,51,52]{} \\
\hline & 1629 & 1621 & 1627 & 1624 & 1628 & 1622 & \\
\hline & 1610 & 1612 & 1616 & 1612 & 1610 & 1609 & \\
\hline \multirow{2}{*}{$\delta \mathrm{CH}_{32}{ }^{+}$} & \multirow{2}{*}{1470} & \multirow{2}{*}{1472} & \multirow{2}{*}{1468} & 1469 & 1465 & 1465 & \multirow{2}{*}[41,46,47,51]{} \\
\hline & & & & 1459 & 1460 & 1459 & \\
\hline$v_{s} \mathrm{COO}^{-}$ & 1415 & 1416 & 1414 & 1413 & 1417 & 1415 & {$[41,46,53]$} \\
\hline$\omega \mathrm{C} \gamma, \tau \mathrm{C} \delta, \tau \mathrm{C} \varepsilon$ & 1348 & 1349 & 1348 & 1347 & 1349 & 1348 & {$[41,46,47]$} \\
\hline $\begin{array}{l}\rho_{\text {as }} \mathrm{NH}_{3}{ }^{+}, \tau \mathrm{C} \beta \\
\mathrm{C} \beta-\mathrm{C} \alpha-\mathrm{H} \alpha, \omega \mathrm{C} \delta\end{array}$ & 1220 & 1222 & - & - & 1222 & 1222 & {$[41,46,47]$} \\
\hline$\rho_{a s} \mathrm{NH}_{3}{ }^{+}, \rho \mathrm{C} \varepsilon$ & 1182 & 1186 & - & - & 1185 & 1186 & {$[41,46,47]$} \\
\hline $\begin{array}{l}\rho_{a s} \mathrm{NH}_{3}{ }^{+} \\
\mathrm{C}-\mathrm{C} \alpha-\mathrm{H} \alpha\end{array}$ & 1148 & 1145 & 1148 & 1161 & 1155 & 1155 & {$[41,46,47]$} \\
\hline \multirow{2}{*}{$\mathrm{PO}_{4}{ }^{3-}, v_{3}$} & - & - & - & 1089 & 1091 & 1099 & \multirow{2}{*}[37,39,54,55]{} \\
\hline & - & - & - & 1027 & 1024 & 1024 & \\
\hline $\mathrm{PO}_{4}{ }^{3-}, v_{1}$ & - & - & - & 970 & 966 & 974 & {$[37,39,54,55]$} \\
\hline \multirow{4}{*}{$\begin{array}{c}v \mathrm{C}-\mathrm{C}, v \mathrm{C}-\mathrm{N} \\
\omega \mathrm{C} \gamma, \tau \mathrm{C} \delta, \tau \mathrm{C} \varepsilon\end{array}$} & 1002 & 1003 & 1007 & 1003 & 1003 & 1003 & \multirow{4}{*}[41,46,47,51,53]{} \\
\hline & 975 & 978 & 979 & 961 & 961 & 978 & \\
\hline & 937 & 935 & 937 & 935 & 935 & 935 & \\
\hline & 911 & 907 & 912 & 912 & 908 & 905 & \\
\hline$\tau, \omega \mathrm{NH}$ & 805 & 802 & - & - & 803 & 803 & {$[41,46]$} \\
\hline \multirow{2}{*}{$\rho \mathrm{CH}_{2}$} & 785 & 782 & 788 & 787 & 782 & 782 & \multirow[b]{3}{*}[47,52,56]{} \\
\hline & 764 & 764 & - & - & - & 764 & \\
\hline $\begin{array}{c}\rho \mathrm{CH}_{2}, v \mathrm{C}-\mathrm{C} \\
\delta \mathrm{COO}\end{array}$ & 704 & - & 708 & 702 & 704 & - & \\
\hline OH (n-cHap) & - & - & - & 632 & 630 & 631 & {$[37,39,54,55]$} \\
\hline \multirow{2}{*}{$\mathrm{PO}_{4}{ }^{3-}, v_{4}$} & \multirow{2}{*}{-} & \multirow{2}{*}{-} & \multirow{2}{*}{-} & 602 & 602 & 601 & \multirow{2}{*}[37,39,54,55]{} \\
\hline & & & & 558 & 559 & 560 & \\
\hline$\rho, \omega, \delta$ & 560 & 562 & 560 & \multirow{2}{*}{554} & 569 & 570 & \multirow{2}{*}[51,57]{} \\
\hline $\mathrm{COO}^{-}$ & 551 & 555 & 553 & & 550 & 547 & \\
\hline $\mathrm{NH}_{3}{ }^{+}$torsion & 477 & $477-480$ & $460-480$ & $464-478$ & 473 & 474 & [57] \\
\hline
\end{tabular}

A detailed analysis of the FTIR spectra of the n-cHAp/L-ArgHCl composite (Figure 5b) showed that vibrations of the phosphate group $\mathrm{PO}_{4}\left(1027 \mathrm{~cm}^{-1}\right.$, valence and strain vibrations of $\mathrm{P}=\mathrm{O}$ and $\mathrm{P}-\mathrm{O}$ bonds) and modes of the $\mathrm{CO}_{3}$ carbonate anion $\left(1420\right.$ and $\left.1450 \mathrm{~cm}^{-1}\right)$ of hydroxyapatite were present in the range of $1700-400 \mathrm{~cm}^{-1}$. Nano-cHAp obtained in our work by liquid-phase synthesis has B-type structural substitution (carbonate anion $\mathrm{CO}_{3}{ }^{2-}$ included in the position of the $\mathrm{PO}_{4}$ group) [37]. After adding the amino acid to n-cHAp, bands in the range of $1470-1450 \mathrm{~cm}^{-1}$ were observed in the spectra of the biocomposites, which correspond to the vibrations of the $\mathrm{C}-\mathrm{H}$ bond in the methylene groups of organic components. The vibrational band at $1400 \mathrm{~cm}^{-1}$ should be related with the total vibrations of the $\mathrm{COO}^{-}$in the L-Arginine molecule, which is in agreement with the literature [41]. The band at $1640-1600 \mathrm{~cm}^{-1}$ should be attributed to the strain vibrations of N-H bonds in amines and $\mathrm{NH}_{3}{ }^{+}$ions, as well as the symmetric and asymmetric strain vibrations of $\mathrm{C}-\mathrm{N}-\mathrm{H}$ bonds in the $\mathrm{CN}_{3} \mathrm{H}_{5}{ }^{+}$group. The bands recorded at $1469 \mathrm{~cm}^{-1}$ and $1460 \mathrm{~cm}^{-1}$ 
correspond to the strain vibrations of $\mathrm{C}-\mathrm{H}$ bonds in the structural fragments of $-\mathrm{CH}-\mathrm{H}^{-}$ and $-\mathrm{CH}_{2}{ }^{-}$.

Table 3. Active modes in the FTIR absorption spectra of L-ArgHCl samples and n-cHAp/L-ArgHCl biocomposites, and their molecular group assignments.

\begin{tabular}{|c|c|c|c|c|c|c|c|}
\hline \multirow{3}{*}{ Active Modes } & \multicolumn{6}{|c|}{ Frequency of the Absorption Bands in the FTIR Spectra of the Samples, $\mathrm{cm}^{-1}$} & \multirow{3}{*}{$\begin{array}{c}\text { Ref.: Study } \\
\text { Reference Number }\end{array}$} \\
\hline & \multicolumn{3}{|c|}{ L-ArgHCl } & \multicolumn{3}{|c|}{ Composites n-cHAp/L-ArgHCl } & \\
\hline & $\mathrm{pH} \leq \mathbf{5}$ & $\mathrm{pH} \geq 7.5$ & $\mathrm{pH} \geq \mathbf{1 1 . 2}$ & $\mathrm{pH} \leq \mathbf{5}$ & $\mathrm{pH} \geq 7.5$ & $\mathrm{pH} \geq 11.2$ & \\
\hline \multirow{2}{*}{$\begin{array}{c}v_{\mathrm{s}} \mathrm{CN}_{3} \mathrm{H}_{5}^{+} \\
v_{\text {as }} \mathrm{NH}_{3}{ }^{+}\end{array}$} & 1678 & 1678 & 1675 & 1680 & 1678 & 1680 & \multirow{2}{*}[41,56,58,59]{} \\
\hline & 1666 & 1669 & 1667 & 1667 & 1669 & 1669 & \\
\hline \multirow{2}{*}{$\begin{array}{c}v_{\text {as }} \mathrm{CN}_{3} \mathrm{H}_{5}{ }^{+} \\
v_{\mathrm{s}} \mathrm{NH}_{3}{ }^{+}\end{array}$} & 1629 & 1630 & 1631 & 1632 & 1630 & 1632 & \multirow{2}{*}[41,56,58,59]{} \\
\hline & 1620 & 1621 & 1621 & 1620 & 1617 & 1619 & \\
\hline$v_{\mathrm{s}} \mathrm{NH}_{3}^{+}$ & 1543 & 1543 & 1543 & 1543 & 1541 & 1541 & {$[41,56,58,59]$} \\
\hline \multirow{2}{*}{$\delta \mathrm{CH}_{2}$} & 1467 & 1467 & 1467 & 1466 & 1472 & 1469 & \multirow{2}{*}[41,56,58,59]{} \\
\hline & 1449 & 1449 & 1449 & 1454 & 1456 & 1449 & \\
\hline$v_{\mathrm{s}} \mathrm{COO}^{-}$ & 1401 & 1401 & 1401 & 1402 & 1398 & 1400 & {$[41,56,58,59]$} \\
\hline $\begin{array}{l}\mathrm{N}-\mathrm{C} \alpha-\mathrm{H} \alpha \\
\mathrm{C} \beta-\mathrm{C} \alpha-\mathrm{H} \alpha\end{array}$ & 1356 & 1362 & 1356 & 1360 & 1361 & 1361 & {$[41,56,58,59]$} \\
\hline $\begin{array}{l}\mathrm{C} \beta \text { twisting, } \\
\mathrm{C} \gamma \text { rocking, } \\
\mathrm{C} \beta-\mathrm{C} \alpha-\mathrm{H} \alpha\end{array}$ & 1307 & 1307 & 1307 & 1307 & 1309 & 1308 & {$[41,56,58,59]$} \\
\hline \multirow{3}{*}{$\delta, \rho \mathrm{NH}_{3}{ }^{+}$} & 1204 & 1205 & 1207 & 1207 & 1212 & 1208 & \multirow{3}{*}[41,56,58,59]{} \\
\hline & 1188 & 1185 & 1185 & 1193 & 1198 & 1195 & \\
\hline & 1167 & 1168 & 1168 & 1153 & 1167 & 1169 & \\
\hline $\mathbf{v}_{\text {as }} \mathrm{CN}_{3} \mathrm{H}_{5}^{+}$ & 1127 & 1123 & 1120 & - & - & - & {$[41,56,58,59]$} \\
\hline \multirow{2}{*}{$v_{3} \mathrm{PO}_{4}{ }^{3-}$} & - & - & - & 1089 & 1091 & 1099 & \multirow{2}{*}[37,39,54,55]{} \\
\hline & - & - & - & 1027 & 1024 & 1024 & \\
\hline$\rho \mathrm{CH}_{2}$ & - & 985 & 983 & - & - & - & {$[41,56,58,59]$} \\
\hline$v \mathrm{C}-\mathrm{C}$ & 885 & 886 & 890 & - & - & - & {$[41,56,58,59]$} \\
\hline$v_{1} \mathrm{PO}_{4}{ }^{3-}$ & - & - & - & 970 & 966 & 974 & {$[37,39,54,55]$} \\
\hline \multirow{2}{*}{$\omega, \delta \mathrm{COO}^{-}$} & 630 & 632 & 639 & \multirow{2}{*}{573} & \multirow{2}{*}{573} & \multirow{2}{*}{574} & \multirow{2}{*}[46]{} \\
\hline & 593 & 594 & 588 & & & & \\
\hline $\mathrm{OH}$ & - & - & - & 629 & 631 & 632 & {$[37,39,54,55]$} \\
\hline \multirow{2}{*}{$v_{4} \mathrm{PO}_{4}{ }^{3-}$} & \multirow{2}{*}{-} & \multirow{2}{*}{ - } & \multirow{2}{*}{ - } & 600 & 600 & 599 & \multirow{2}{*}[37,39,54,55]{} \\
\hline & & & & 559 & 558 & 558 & \\
\hline$\tau \mathrm{NH}_{3}{ }^{+}$ & 526 & 525 & 524 & 530 & 526 & 524 & {$[41,56,58,59]$} \\
\hline
\end{tabular}

The appearance of a certain aggregation of n-cHAp crystals in the amino acid matrix $\mathrm{L}$-ArgHCl, previously detected by X-ray diffractometry, was observed in the changes of the intensity in the absorption bands of the $\mathrm{PO}_{4}$ phosphate-oxygen group at $1088 \mathrm{~cm}^{-1}$ and $962 \mathrm{~cm}^{-1}$ ( $v_{3}$ bending and $v_{1}$ stretching, respectively). In addition, significant changes occurred in the intensity of the modes around $1220 \mathrm{~cm}^{-1}$ and $1185 \mathrm{~cm}^{-1}$ assigned to the bending and rocking vibrations of $\mathrm{N}-\mathrm{H}$ bonds in $\mathrm{NH}_{3}{ }^{+} \mathrm{L}$-Arginine ions in the media with different $\mathrm{pH}$.

The results obtained by FTIR spectroscopy are in agreement with the X-ray diffraction analysis. These findings indicate the electrostatic interaction between the $\mathrm{L}-\mathrm{ArgHCl}$ molecule and the carbonate-substituted calcium hydroxyapatite n-cHAp. 


\section{Discussion}

In order to restore dental enamel, a number of various materials have been developed, such as composite resins and ceramics [60,61]; however, their application could not result in the achievement of a stable restoration due to imperfections in the combination of the utilized materials and the native dental tissue [12,62]. Therefore, a tendency to reproduce the native structure of the natural hard dental tissue $[13,14,62]$ with the use of biomimetic composites involving nanocrystalline carbonate-substituted hydroxyapatite in its composition is in the basis of the doctrine of current therapeutic dentistry.

Improving the integration of biocomposites with natural dental tissue and regenerating tissue using a biomimetic strategy requires an understanding of the mechanisms of interaction between the artificial and natural materials in the nano- and microscales $[40,63,64]$. The results of a comparative analysis of the data obtained by a set of structural and spectroscopic diagnostic methods reveal the differences in the mechanisms of amino acidnanocrystalline hydroxyapatite interactions, depending on the $\mathrm{pH}$ value of the solution from which the $\mathrm{n}$-cHAp/L-LysHCl and n-cHAp/L-ArgHCl biomimetic composites were crystallised (Figures 1-5).

First, X-ray diffraction data confirm that the hydroxyapatite synthesized using our technique [37], which was used to obtain the n-cHAp/L-LysHCl and n-cHAp/L-ArgHCl composites, is nanocrystalline and has magnesium, sodium and fluoride ions in its structure, which was confirmed for these samples by previous X-ray photoelectron spectroscopy (XPS) studies [37].

Second, the results of $X$-ray diffraction phase analysis of the amino acids crystallized from media with different $\mathrm{pH}$ values agree with previously published data on the change in the charge state of L-Lysine and L-Arginine under increased or decreased medium acidity [41,52], which is reflected in the redistribution of the diffraction peak intensities. Thus, the increased intensity of the diffraction reflex (300) of n-cHAp in the presence of LArginine in the charged state means the influence of the amino acid on the orientation of the n-cHAp crystals [65]. In turn, orientation of the n-cHAp crystals in the n-cHAp/L-LysHCl biocomposite changes only when L-Lysine is positively charged, above the isoelectric point $(\mathrm{pH}<8.7)$. The ratio of the intensities of the L-Lysine diffraction reflexes (150) and (420) in the $\mathrm{n}$-cHAp/L-LysHCl biocomposite at $\mathrm{pH} \leq 5$ is similar to the ratio of these peaks for L-Lysine sample in the anionic form $(\mathrm{pH} \geq 11.2)$, indicating the charge compensation that occurs between hydroxyapatite and L-Lysine (Figure 2a).

Analysis of the FTIR spectrum of the synthesised n-cHAp showed (Figure 5a,b curve 1) that this sample is characterised by the presence of low-intensity absorption bands corresponding to the valence and strain vibrations of structurally bonded $\mathrm{OH}$ groups at $630 \mathrm{~cm}^{-1}$. It should be noted that the intensity of the absorption bands of $\mathrm{OH}$ groups in the spectra of the n-cHAp samples (Figure 5) is significantly lower than in the spectrum of the stoichiometric HAp sample [66]. It has been repeatedly shown that isomorphic substitutions in the structure of hydroxyapatite lead to the formation of various defects, including vacancies in the positions of $\mathrm{OH}$ groups [67]. Thus, the crystal structure of the n-cHAp samples synthesized in our work is characterized by the substitution of the phosphate ion $\mathrm{PO}_{4}{ }^{3-}$ by the $\mathrm{CO}_{3}{ }^{2-}$ group (B-type of substitution). Absorption bands of $\mathrm{CO}_{3}$ groups in the spectra of n-cHAp samples were recorded in the range of $1400-1470 \mathrm{~cm}^{-1}$. The formation of defects in the n-cHAp crystal lattice leads to a decrease of the intensity of absorption bands for $\mathrm{OH}$ groups in the FTIR spectra of the synthesized samples (Figure $5 \mathrm{a}, \mathrm{b}$ curve 1 ).

The FTIR spectra of all the biomimetic synthesised composites showed absorption bands that could not be assigned to n-cHAp or the corresponding amino acid (Figure 5a,b curves $2,3,4)$.

The results of the FTIR spectroscopic investigation of the change in the charge state of L-Lysine in the environments with different alkalinity are consistent with the results of $\mathrm{X}$-ray diffraction analysis as evidenced by the redistribution of intensities of modes in the spectra correlated with the side chains, i.e., amide and carboxyl groups, of the amino acid. The assumption of charge compensation between n-cHAp and L-Lysine in the cationic 
form is also confirmed, as evidenced by the changes in the ratio of intensities of modes attributed to the $\mathrm{OH}$ groups of hydroxyapatite and the vibrations of the phosphorusoxygen tetrahedrons acid (Figure 5a curves 2,3,4). It can be concluded that the interaction between n-cHAp and L-Lysine occurs through the formation of chemical bonds. Binding between the $\mathrm{PO}_{4}{ }^{3-}$ group of $\mathrm{n}$-cHAp and the $\mathrm{NH}_{3}{ }^{+}$group of L-Lysine occurs mainly in an acidic $(\mathrm{pH} \leq 5)$ environment, whereas the substitution of $\mathrm{OH}$ groups of hydroxyapatite by the carboxyl group of L-Lysine occurs mainly in an alkaline environment. The adsorbed amino acids molecules occupy the Ca and P sites of the HAP surfaces. Thus, L-Lysine changes its charge state with increased or decreased alkalinity of the environment, and $\mathrm{n}$-cHAp participates in the neutralisation reaction with L-Lysine in cationic form. These processes of interaction were previously simulated in $[16,41,68]$.

As for the samples of L-Arginine crystallised from the media with different $\mathrm{pH}$ values, small redistributions of the intensities of modes attributed to the vibrations of amide groups are observed depending on the medium acidity (Figure $4 \mathrm{~b}$ ). This observation represents changes in the conformation of L-Arginine molecules in the environments with different acidities $[41,65]$. The introduction of $n$-cHAp into the L-Arginine matrix leads to a change in the intensity of absorption bands near $1090 \mathrm{~cm}^{-1}$ and $962 \mathrm{~cm}^{-1}$, related to the vibrations of phosphorus-oxygen tetrahedrons of hydroxyapatite (Figure 5b). In addition, a redistribution in the intensities of modes attributed to the vibrations of LArginine amide groups in the samples of $\mathrm{n}$-cHAp/L-ArgHCl prepared at the increased and decreased alkalinity is observed. The presence of an additional $\mathrm{NH}_{3}{ }^{+}$group in L-Arginine hydrochloride and the absence of a $\mathrm{COO}^{-}$side chain led to the mutual orientation of L-Arginine hydrochloride and n-cHAp molecules. Thus, the X-ray diffraction and infrared spectroscopy results confirm that the changes in the molecular composition of biomimetic composites are caused by the electrostatic interaction between the $\mathrm{L}-\mathrm{ArgHCl}$ molecule and the carbonate-substituted calcium hydroxyapatite.

Thus, the problems of bio-inspired material synthesis dealt with in our work, as well as the establishing of the mechanisms of organic-mineral interaction in biomimetic composites, will enable the achievement of optimal biocompatibility between the native tissue and dental biocomposite, and, as a result, to develop an optimal therapeutic approach for the treatment of dental diseases.

\section{Conclusions}

Using structural and spectroscopic analysis methods, differences in the surface interaction of nanocrystalline non-stoichiometric carbonate-substituted hydroxyapatite and the polar amino acids L-Lysine hydrochloride and L-Arginine hydrochloride in acidic and alkaline media were established.

X-ray diffraction data confirm that the hydroxyapatite synthesized using our technique, which was used to create the n-cHAp/L-LysHCl and n-cHAp/L-ArgHCl composites, is nanocrystalline and has magnesium, sodium and fluoride ions in its structure that was confirmed for these samples by our previous XPS studies. The results show that L-Arginine hydrochloride retains its amorphous structure in the presence of hydroxyapatite. Thus, with the formation of $\mathrm{n}-\mathrm{cHAp} / \mathrm{L}-\mathrm{LysHCl}$ biocomposites, the directional agglomeration of hydroxyapatite occurs, unlike in n-cHAp/L-ArgHCl biocomposites, for which a homogeneous distribution of hydroxyapatite in the amino acid matrix is observed.

Studies of molecular composition of the samples by Fourier transform infrared spectroscopy under the change in the charge state of L-Lysine in environments with different alkalinity are consistent with the results of X-ray diffraction analysis, as is evidenced by the redistribution of intensities of modes in the spectra correlated with the side chains, i.e., amide and carboxyl groups, of the amino acid. The formation of a biocomposite containing nanocrystalline non-stoichiometric carbonate-substituted hydroxyapatite and L-Lysine occurs through the formation of chemical bonds. Binding between the $\mathrm{PO}_{4}{ }^{3-}$ group of n-cHAp and the $\mathrm{NH}_{3}{ }^{+}$group of L-Lysine occurs mainly in an acidic $(\mathrm{pH} \leq 5)$ environment, whereas the substitution of $\mathrm{OH}$ groups of hydroxyapatite by the carboxyl 
group of L-Lysine occurs mainly in an alkaline environment. The results of the structural and spectroscopic analysis indicate the chemical adsorption of L-Lysine onto the surface of the hydroxyapatite.

Corresponding studies of the molecular structure of biomimetic composites containing L-Arginine showed that the interaction of this amino acid with the carbonate-substituted hydroxyapatite involved mechanisms of molecular orientation observed through changing of vibrational modes correlated with the carbon chain and the guanidine group $\left(\mathrm{CN}_{3} \mathrm{H}_{5}{ }^{+}\right)$of $\mathrm{L}$-Arginine, and also weakly depends on the $\mathrm{pH}$ value of the medium. The $\mathrm{X}$-ray diffraction and infrared spectroscopy results confirm that changes in the molecular composition of $\mathrm{n}-\mathrm{cHAp} / \mathrm{L}-\mathrm{ArgHCl}$ biomimetic composites are caused by the electrostatic interaction between the $\mathrm{L}-\mathrm{ArgHCl}$ molecule and the carbonate-substituted calcium hydroxyapatite.

The revealed mechanisms of interaction of $n$-cHAp, with a set of physicochemical properties characteristic for the apatite of human tooth enamel, and specific polar amino acids, are crucial for selecting of the formation conditions for biomimetic composites and their integration with natural dental tissue.

Author Contributions: Conceptualization, P.S. and D.G.; methodology, P.S. and D.G.; software, D.G.; validation, P.S. and D.G.; formal analysis, P.S. and D.G.; investigation, P.S.,D.G., V.K. and K.N.; resources, P.S.; data curation, P.S. and D.G.; writing—original draft preparation, P.S.,D.G., V.K. and K.N.; writing - review and editing, P.S. and D.G.; visualization, D.G.; supervision, P.S.; project administration, P.S. and D.G.; funding acquisition, P.S. All authors have read and agreed to the published version of the manuscript.

Funding: This work was funded by the grant of the Russian Science Foundation, grant number 21-75-10005. The access to scientific equipment and methodology was provided under support of the Ministry of Science and Higher Education of Russia, under Agreement N 075-15-2021-1351.

Institutional Review Board Statement: Not applicable.

Informed Consent Statement: Not applicable.

Data Availability Statement: The data that support the findings of this study are available from the corresponding author upon reasonable request.

Acknowledgments: A part of this research was undertaken at the Infrared Microspectroscopy (IRM) beamline at the Australian Synchrotron.

Conflicts of Interest: The authors declare no conflict of interest.

\section{References}

1. Chun, H.J.; Park, K.; Kim, C.-H.; Khang, G. Novel Biomaterials for Regenerative Medicine; Springer: Berlin/Heidelberg, Germany, 2018; ISBN 9789811309472.

2. Upadhyay, A.; Pillai, S.; Khayambashi, P.; Sabri, H.; Lee, K.T.; Tarar, M.; Zhou, S.; Harb, I.; Tran, S.D. Biomimetic aspects of oral and dentofacial regeneration. Biomimetics 2020, 5, 51. [CrossRef] [PubMed]

3. Mousavi, S.M.; Yousefi, K.; Hashemi, S.A.; Afsa, M.; Bahrani, S.; Gholami, A.; Ghahramani, Y.; Alizadeh, A.; Chiang, W.-H. Renewable carbon nano-materials: Novel resources for dental tissue engineering. Nanomaterials 2021, 11, 2800. [CrossRef] [PubMed]

4. Katti, D.R.; Sharma, A.; Ambre, A.H.; Katti, K.S. Molecular interactions in biomineralized hydroxyapatite amino acid modified nanoclay: In silico design of bone biomaterials. Mater. Sci. Eng. C 2015, 46, 207-217. [CrossRef] [PubMed]

5. Seredin, P.V.; Goloshchapov, D.L.; Prutskij, T.; Ippolitov, Y.u.A. Fabrication and characterisation of composites materials similar optically and in composition to native dental tissues. Results Phys. 2017, 7, 1086-1094. [CrossRef]

6. Pina, S.; Oliveira, J.M.; Reis, R.L. Biomimetic strategies to engineer mineralized human tissues. In Handbook of Bioceramics and Biocomposites; Antoniac, I.V., Ed.; Springer International Publishing: Cham, Switzerland, 2016; pp. 503-519. ISBN 978-3-319-12460-5.

7. Turon, P.; del Valle, L.; Alemán, C.; Puiggalí, J. Biodegradable and biocompatible systems based on hydroxyapatite nanoparticles. Appl. Sci. 2017, 7, 60. [CrossRef]

8. Nemati, E.; Gholami, A. Nano bacterial cellulose for biomedical applications: A mini review focus on tissue engineering. Adv. Appl. NanoBio Technol. 2021, 2, 93-101.

9. Gholami, A.; Hashemi, S.A.; Yousefi, K.; Mousavi, S.M.; Chiang, W.-H.; Ramakrishna, S.; Mazraedoost, S.; Alizadeh, A.; Omidifar, N.; Behbudi, G.; et al. 3D nanostructures for tissue engineering, cancer therapy, and gene delivery. J. Nanomater. 2020, 2020, e1852946. [CrossRef] 
10. Memarpour, M.; Shafiei, F.; Rafiee, A.; Soltani, M.; Dashti, M.H. Effect of hydroxyapatite nanoparticles on enamel remineralization and estimation of fissure sealant bond strength to remineralized tooth surfaces: An in vitro study. BMC Oral Health 2019, 19, 92. [CrossRef] [PubMed]

11. Alipour, A. Virus decorated nanobiomaterials as scaffolds for tissue engineering. Adv. Appl. NanoBio Technol. $2021,2,79-85$.

12. Barot, T.; Rawtani, D.; Kulkarni, P. Nanotechnology-based materials as emerging trends for dental applications. Rev. Adv. Mater. Sci. 2021, 60, 173-189. [CrossRef]

13. Zafar, M.S.; Amin, F.; Fareed, M.A.; Ghabbani, H.; Riaz, S.; Khurshid, Z.; Kumar, N. Biomimetic aspects of restorative dentistry biomaterials. Biomimetics 2020, 5, 34. [CrossRef] [PubMed]

14. Wang, J.; Liu, Z.; Ren, B.; Wang, Q.; Wu, J.; Yang, N.; Sui, X.; Li, L.; Li, M.; Zhang, X.; et al. Biomimetic mineralisation systems for in situ enamel restoration inspired by amelogenesis. J. Mater. Sci. Mater. Med. 2021, 32, 1-17. [CrossRef]

15. Dorozhkin, S.V. Hydroxyapatite and Other Calcium Orthophosphates: Bioceramics, Coatings and Dental Applications [Hardcover]; Nova Science Publishers, Inc.: New York, NY, USA, 2017; ISBN 978-1-5361-1897-1.

16. Comeau, P.; Willett, T. Impact of side chain polarity on non-stoichiometric nano-hydroxyapatite surface functionalization with amino acids. Sci. Rep. 2018, 8, 1-11. [CrossRef] [PubMed]

17. Palazzo, B.; Walsh, D.; Iafisco, M.; Foresti, E.; Bertinetti, L.; Martra, G.; Bianchi, C.L.; Cappelletti, G.; Roveri, N. Amino acid synergetic effect on structure, morphology and surface properties of biomimetic apatite nanocrystals. Acta Biomater. 2009, 5, 1241-1252. [CrossRef] [PubMed]

18. Tavafoghi, M.; Cerruti, M. The role of amino acids in hydroxyapatite mineralization. J. R. Soc. Interface 2016, 13, 20160462. [CrossRef]

19. Lagazzo, A.; Barberis, F.; Carbone, C.; Ramis, G.; Finocchio, E. Molecular level interactions in brushite-aminoacids composites. Mater. Sci. Eng. C Mater. Biol. Appl. 2017, 70, 721-727. [CrossRef]

20. El Rhilassi, A.; Mourabet, M.; Bennani-Ziatni, M.; El Hamri, R.; Taitai, A. Interaction of some essential amino acids with synthesized poorly crystalline hydroxyapatite. J. Saudi Chem. Soc. 2016, 20 (Suppl. S1), S632-S640. [CrossRef]

21. Tavafoghi Jahromi, M.; Cerruti, M. Amino acid/ion aggregate formation and their role in hydroxyapatite precipitation. Cryst. Growth Des. 2015, 15, 1096-1104. [CrossRef]

22. Lin, Z.; Hu, R.; Zhou, J.; Ye, Y.; Xu, Z.; Lin, C. A further insight into the adsorption mechanism of protein on hydroxyapatite by FTIR-ATR spectrometry. Spectrochim. Acta Part A Mol. Biomol. Spectrosc. 2017, 173, 527-531. [CrossRef] [PubMed]

23. Gómez-Morales, J.; Delgado-López, J.M.; Iafisco, M.; Hernández-Hernández, A.; Prat, M. Amino acidic control of calcium phosphate precipitation by using the vapor diffusion method in microdroplets. Cryst. Growth Des. 2011, 11, 4802-4809. [CrossRef]

24. Rimola, A.; Corno, M.; Garza, J.; Ugliengo, P. Ab initio modelling of protein-biomaterial interactions: Influence of amino acid polar side chains on adsorption at hydroxyapatite surfaces. Phil. Trans. R. Soc. A 2012, 370, 1478-1498. [CrossRef]

25. Katti, K.S.; Ambre, A.H.; Peterka, N.; Katti, D.R. Use of unnatural amino acids for design of novel organomodified clays as components of nanocomposite biomaterials. Philos. Trans. R. Soc. Lond. A Math. Phys. Eng. Sci. 2010, 368, 1963-1980. [CrossRef] [PubMed]

26. Otsuka, Y.; Ito, A.; Takeuchi, M.; Tanaka, H. Effect of amino acid on calcium phosphate phase transformation: Attenuated total reflectance-infrared spectroscopy and chemometrics. Colloid Polym. Sci. 2019, 297, 155-163. [CrossRef]

27. da Silva, C.M.F.; de Menezes Costa, A.F.; Costa, A.R.; Neves, J.G.; de Godói, A.P.T.; de Góes, V.F.F. Influence of different acid etching times on the shear bond strength of brackets bonded to bovine enamel. Saudi Dent. J. 2021, 33, 474-480. [CrossRef]

28. Erceg, I.; Maltar-Strmečki, N.; Jurašin, D.D.; Strasser, V.; Ćurlin, M.; Lyons, D.M.; Radatović, B.; Mlinarić, N.M.; Kralj, D.; Sikirić, M.D. Comparison of the effect of the amino acids on spontaneous formation and transformation of calcium phosphates. Crystals 2021, 11, 792. [CrossRef]

29. Mukherjee, K.; Ruan, Q.; Nutt, S.; Tao, J.; De Yoreo, J.J.; Moradian-Oldak, J. Peptide-based bioinspired approach to regrowing multilayered aprismatic enamel. ACS Omega 2018, 3, 2546-2557. [CrossRef]

30. Ding, L.; Han, S.; Wang, K.; Zheng, S.; Zheng, W.; Peng, X.; Niu, Y.; Li, W.; Zhang, L. Remineralization of enamel caries by an amelogenin-derived peptide and fluoride in vitro. Regen. Biomater. 2020, 7, 283-292. [CrossRef] [PubMed]

31. Sullivan, R.; Rege, A.; Corby, P.; Klaczany, G.; Allen, K.; Hershkowitz, D.; Goldder, B.; Wolff, M. Evaluation of a dentifrice containing $8 \%$ arginine, calcium carbonate, and sodium monofluorophosphate to repair acid-softened enamel using an intra-oral remineralization model. J. Clin. Dent. 2014, 25, A14-A19.

32. Mousavi, S.M.; Hashemi, S.A.; Salahi, S.; Hosseini, M.; Amani, A.; Babapoor, A. Development of Clay Nanoparticles Toward Bio and Medical Applications; IntechOpen: London, UK; Rijeka, Croatia, 2018; pp. 167-191. ISBN 978-1-78923-728-3.

33. Mousavi, S.M.; Zarei, M.; Hashemi, S.A.; Ramakrishna, S.; Lai, C.W.; Chiang, W.-H.; Gholami, A.; Omidifar, N.; Shokripour, M. Asymmetric membranes: A potential scaffold for wound healing applications. Symmetry 2020, 12, 1100. [CrossRef]

34. Mousavi, S.-M.; Nejad, Z.M.; Hashemi, S.A.; Salari, M.; Gholami, A.; Ramakrishna, S.; Chiang, W.-H.; Lai, C.W. Bioactive agent-loaded electrospun nanofiber membranes for accelerating healing process: A review. Membranes 2021, 11, 702. [CrossRef]

35. Ashoori, Y.; Mohkam, M.; Heidari, R.; Abootalebi, S.N.; Mousavi, S.M.; Hashemi, S.A.; Golkar, N.; Gholami, A. Development and in vivo characterization of probiotic lysate-treated chitosan nanogel as a novel biocompatible formulation for wound healing. BioMed Res. Int. 2020, 2020, e8868618. [CrossRef]

36. Combes, C.; Cazalbou, S.; Rey, C. Apatite biominerals. Minerals 2016, 6, 34. [CrossRef] 
37. Goloshchapov, D.L.; Lenshin, A.S.; Savchenko, D.V.; Seredin, P.V. Importance of defect nanocrystalline calcium hydroxyapatite characteristics for developing the dental biomimetic composites. Results Phys. 2019, 13, 102158. [CrossRef]

38. Seredin, P.; Goloshchapov, D.; Kashkarov, V.; Ippolitov, Y.; Bambery, K. The investigations of changes in mineral-organic and carbon-phosphate ratios in the mixed saliva by synchrotron infrared spectroscopy. Results Phys. 2016, 6, 315-321. [CrossRef]

39. Seredin, P.; Goloshchapov, D.; Ippolitov, Y.; Vongsvivut, J. Development of a new approach to diagnosis of the early fluorosis forms by means of FTIR and Raman microspectroscopy. Sci. Rep. 2020, 10, 20891. [CrossRef] [PubMed]

40. Seredin, P.; Goloshchapov, D.; Ippolitov, Y.; Vongsvivut, J. Engineering of a biomimetic interface between a native dental tissue and restorative composite and its study using synchrotron FTIR microscopic mapping. Int. J. Mol. Sci. 2021, 22, 6510. [CrossRef] [PubMed]

41. Hernández, B.; Pflüger, F.; Derbel, N.; De Coninck, J.; Ghomi, M. Vibrational analysis of amino acids and short peptides in hydrated media. VI. amino acids with positively charged side chains: L-Lysine and L-Arginine. J. Phys. Chem. B 2010, 114, 1077-1088. [CrossRef]

42. Brasinika, D.; Tsigkou, O.; Tsetsekou, A.; Missirlis, Y.F. Bioinspired synthesis of hydroxyapatite nanocrystals in the presence of collagen and L-Arginine: Candidates for bone regeneration. J. Biomed. Mater. Res. 2015. [CrossRef]

43. Pazderka, T.; Kopecký, V. Drop coating deposition Raman spectroscopy of proteinogenic amino acids compared with their solution and crystalline state. Spectrochim. Acta Part A Mol. Biomol. Spectrosc. 2017, 185, 207-216. [CrossRef]

44. Seredin, P.; Goloshchapov, D.; Ippolitov, Y. Pimm vongsvivut pathology-specific molecular profiles of saliva in patients with multiple dental caries-potential application for predictive, preventive and personalised medical services. EPMA J. 2018, 9, 195-203. [CrossRef] [PubMed]

45. Barth, A. The infrared absorption of amino acid side chains. Prog. Biophys. Mol. Biol. 2000, 74, 141-173. [CrossRef]

46. Wolpert, M.; Hellwig, P. Infrared spectra and molar absorption coefficients of the 20 alpha amino acids in aqueous solutions in the spectral range from 1800 to $500 \mathrm{~cm}^{-1}$. Spectrochim. Acta Part A Mol. Biomol. Spectrosc. 2006, 64, 987-1001. [CrossRef] [PubMed]

47. Paiva, F.M.; Batista, J.C.; Rêgo, F.S.C.; Lima, J.A.; Freire, P.T.C.; Melo, F.E.A.; Mendes Filho, J.; de Menezes, A.S.; Nogueira, C.E.S. Infrared and Raman spectroscopy and DFT calculations of DL amino acids: Valine and lysine hydrochloride. J. Mol. Struct. 2017, 1127, 419-426. [CrossRef]

48. Ye, Q.; Spencer, P. Analyses of material-tissue interfaces by Fourier transform infrared, Raman spectroscopy, and chemometrics. In Material-Tissue Interfacial Phenomena; Elsevier: Amsterdam, The Netherlands, 2017; pp. 231-251. ISBN 978-0-08-100330-5.

49. Seredin, P.; Goloshchapov, D.; Kashkarov, V.; Ippolitov, Y.; Ippolitov, I.; Vongsvivut, J. To the question on the use of multivariate analysis and 2D visualisation of synchrotron ATR-FTIR chemical imaging spectral data in the diagnostics of biomimetic sound dentin/dental composite interface. Diagnostics 2021, 11, 1294. [CrossRef] [PubMed]

50. Garrido, C.; Aguayo, T.; Clavijo, E.; Gómez-Jeria, J.S.; Campos-Vallette, M.M. The effect of the PH on the interaction of L-Arginine with colloidal silver nanoparticles. A Raman and SERS study: Effect of PH on interaction of Arg with colloidal AgNps. J. Raman Spectrosc. 2013, 44, 1105-1110. [CrossRef]

51. Tao, M.; Zhu, M.; Wu, C.; He, Z. Degradation kinetic study of lysine in lysine hydrochloride solutions for injection by determining its main degradation product. Asian J. Pharm. Sci. 2015, 10, 57-63. [CrossRef]

52. Rozenberg, M.; Shoham, G. FTIR spectra of solid poly-L-Lysine in the stretching NH mode range. Biophys. Chem. 2007, 125, 166-171. [CrossRef] [PubMed]

53. Boeckx, B.; Maes, G. Experimental and theoretical observation of different intramolecular H-bonds in lysine conformations. J. Phys. Chem. B 2012, 116, 12441-12449. [CrossRef]

54. Drouet, C. Apatite formation: Why it may not work as planned, and how to conclusively identify apatite compounds. BioMed Res. Int. 2013, 2013, 490946. [CrossRef] [PubMed]

55. Rey, C.; Marsan, O.; Combes, C.; Drouet, C.; Grossin, D.; Sarda, S. Characterization of calcium phosphates using vibrational spectroscopies. In Advances in Calcium Phosphate Biomaterials; Springer Series in Biomaterials Science and Engineering; Springer: Berlin/Heidelberg, Germany, 2014; pp. 229-266. ISBN 978-3-642-53979-4.

56. Aliaga, A.E.; Garrido, C.; Leyton, P.; Diaz, F.G.; Gomez-Jeria, J.S.; Aguayo, T.; Clavijo, E.; Campos-Vallette, M.M.; Sanchez-Cortes, S. SERS and theoretical studies of arginine. Spectrochim. Acta Part A Mol. Biomol. Spectrosc. 2010, 76, 458-463. [CrossRef] [PubMed]

57. Matei, A.; Drichko, N.; Gompf, B.; Dressel, M. Far-infrared spectra of amino acids. Chem. Phys. 2005, 316, 61-71. [CrossRef]

58. Sunatkari, A.L.; Talwatkar, S.S.; Tamgadge, Y.S.; Muley, G.G. Synthesis, characterization and optical properties of L-Arginine stabilized gold nanocolloids. Nanosci. Nanotechnol. 2015, 5, 30-35.

59. Ji, Z.; Santamaria, R.; Garzón, I.L. Vibrational circular dichroism and IR absorption spectra of amino acids: A density functional study. J. Phys. Chem. A 2010, 114, 3591-3601. [CrossRef] [PubMed]

60. Antoniac, I.V. Handbook of Bioceramics and Biocomposites; Antoniac, I.V., Ed.; Springer International Publishing: Cham, Switzerland, 2016; ISBN 978-3-319-12459-9.

61. O'Brien, W.J. (Ed.) Dental Materials and Their Selection, 4th ed.; Quintessence Pub. Co.: Hanover Park, IL, USA, 2008; ISBN 978-0-86715-437-5.

62. El Gezawi, M.; Wölfle, U.C.; Haridy, R.; Fliefel, R.; Kaisarly, D. Remineralization, regeneration, and repair of natural tooth structure: Influences on the future of restorative dentistry practice. ACS Biomater. Sci. Eng. 2019, 5, 4899-4919. [CrossRef] [PubMed] 
63. Goloshchapov, D.; Buylov, N.; Emelyanova, A.; Ippolitov, I.; Ippolitov, Y.; Kashkarov, V.; Khudyakov, Y.; Nikitkov, K.; Seredin, P. Raman and XANES spectroscopic study of the influence of coordination atomic and molecular environments in biomimetic composite materials integrated with dental tissue. Nanomaterials 2021, 11, 3099. [CrossRef] [PubMed]

64. Yanyan, S.; Guangxin, W.; Guoqing, S.; Yaming, W.; Wuhui, L.; Osaka, A. Effects of amino acids on conversion of calcium carbonate to hydroxyapatite. RSC Adv. 2020, 10, 37005-37013. [CrossRef]

65. Saranya, S.; Samuel Justin, S.J.; Vijay Solomon, R.; Wilson, P. L-Arginine directed and ultrasonically aided growth of nanocrystalline hydroxyapatite particles with tunable morphology. Colloids Surf. A Physicochem. Eng. Asp. 2018, 538, 270-279. [CrossRef]

66. Markovic, M.; Fowler, B.O.; Tung, M.S. Preparation and comprehensive characterization of a calcium hydroxyapatite reference material. J. Res. Natl. Inst. Stand. Technol. 2004, 109, 553. [CrossRef]

67. Cacciotti, I. Multisubstituted hydroxyapatite powders and coatings: The influence of the codoping on the hydroxyapatite performances. Int. J. Appl. Ceram. Technol. 2019, 16, 1864-1884. [CrossRef]

68. Zhang, Z.; Pan, H.; Tang, R. Molecular dynamics simulations of the adsorption of amino acids on the hydroxyapatite $\{100\}$-water interface. Front. Mater. Sci. China 2008, 2, 239-245. [CrossRef] 